\title{
Research Paper: Organization and Preparedness of Emergency and Disaster Medical Response Teams: Obstacles and Challenges
}

\author{
Yosouf Akbari Shahrestanaki $^{1}$ (D), Hamidreza Khankeh ${ }^{1,2^{*}}$ (D), Gholamreza Masoumi ${ }^{3}$, Mohammadali Hosseini ${ }^{4}$ \\ 1. Research Center for Emergency and Disaster Health, University of Social Welfare and Rehabilitation Sciences, Tehran, Iran. \\ 2. Department of Clinical Science and Education, Karolinska Institute, Stockholm, Sweden. \\ 3. Trauma \& Injury Research Center, Iran University of Medical Sciences, Tehran, Iran. \\ 4. Department of Nursing, University of Social Welfare and Rehabilitation Sciences, Tehran, Iran.
}

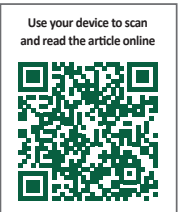

Citation: Akbari Shahrestanaki Y, Khankeh HR, Masoumi Gh, Hosseini MA. Organization and Preparedness of Emergency and Disaster Medical Response Teams: Obstacles and Challenges. Health in Emergencies and Disasters Quarterly. 2020; 5(4):169-182. http://dx.doi.org/10.32598/hdq.5.4.155.1

http://dx.doi.org/10.32598/hdq.5.4.155.1

Article info:

Received: 27 Jan 2020

Accepted: 11 May 2020

Available Online: 01 Jul 2020

\section{Keywords:}

Organization, Preparedness, Emergency and Disaster, Emergency Medical Team, Obstacles and Challenges

\begin{abstract}
A B S T R ACT
Background: Rising trend of emergencies and disasters in the world has caused a lot of damage to the health care facility infrastructures. This has led the health needs of the affected population to be the first and most requirement in emergencies and disasters. In most countries for the timely and appropriate response to the health needs of the affected areas, structured and organized teams are formed. Given the frequent occurrence of events in Iran and the adverse effects of emergencies and disasters on the community health, this study aimed to investigate the obstacles and challenges associated with the organization and preparation of Iran's Emergencies and Disasters Medical Response Teams (EDMRT).

Materials and Methods: In this study, a qualitative approach with a content analysis method was used to explore and extract the obstacles and challenges of the medical response teams in the field of organization and preparation. Data collection was done through 18 in-depth, unstructured, and semistructured interviews with 16 experts and experienced people who were purposefully selected. Besides the interview, field visits and related reports were used to confirm or reject the findings. Data analysis was done by the qualitative approach recommended by Graneheim.

Results: The obstacles and challenges associated with the organization and preparation of teams were obtained under 1 theme, 2 categories, and 10 subcategories. The main theme was "team management". The categories included unorganized groups and frangible readiness. Concepts of the team; unknown structure, lack of effective leadership/command, poor supervision of proctor organization, membership; complex process, heterogeneous composition are the sub-categories related to the first category. And concepts of local level; disable to establishment a team; disaster medicine, unfamiliar concept; lack of air care team; dependence versus self-sufficiency; non-systematically support; and inappropriate location of deployment are the sub-categories of the second category

Conclusion: The results of the study show that the current structures for medical response in emergencies and disasters have numerous challenges in terms of organization and preparedness This defect harms the performance and effectiveness of medical response teams and an obstacle to the overall policy of reducing damages in disasters. The present study illustrates the need to review and refine the organization and preparedness processes associated with the current structure of medical response teams in emergencies and disasters. Of course, it is recommended that a more comprehensive study be conducted to identify and address the other areas of influence in these teams, such as legal considerations, health and safety, and related security issues.
\end{abstract}

\section{* Corresponding Author:}

Hamidreza Khankeh, PhD.

Address: Research Center for Emergency and Disaster Health, University of Social Welfare and Rehabilitation Sciences, Tehran, Iran.

E-mail: hamid.khankeh@ki.se 


\section{Introduction}

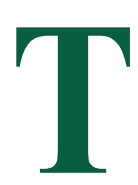

he course of historical developments of human life on Earth and the increasing frequency of accidents and disasters indicate that disasters can happen at any time and place. Given the environmental, demographic, and climate changes, communities are increasingly at risk of accidents, disasters, and harsh consequences $[1,2]$. In recent years, natural disasters have occurred frequently around the world, causing severe human losses and property damages [3]. A total of 315 climate and geological disasters have been recorded in the International Disaster Database (EM-DAT) in 2018. The results of the above disasters were 11804 death, and more than 68 million people affected worldwide [4]. The health system defines a catastrophe or accident with a Mass Casualty Incident (MCI) as an event that increases the short-term, medium-term, and long-term medical needs due to a large number of patients and the injured, against the response capacity of the affected area.

This imbalance can be due to the quantitative reduction of resources (human resources and equipment), the reduction of the quality of services provided, as well as organizational or operational weaknesses [5]. Health services are always one of the most critical demands of people after the occurrence of accidents and disasters; because the most critical concern among the many consequences of disasters is the damage to health [6]. In the case of accidents and disasters, the medical system aims to provide timely medical care to prevent death and disability of affected individuals [7]. One of the priorities for disaster risk reduction mentioned in the International Sendai Document 2015-2030 is "to increase preparedness to provide an effective response to the effects of disasters at all national, local and regional levels" which emphasizes the provision of effective health services in the event of accidents and disasters [8].

One of the appropriate strategies to achieve the goals mentioned in the abovementioned priority is to strengthen the capacity of medical response at the local level through planning, practicing, and learning from mistakes [9]. The formation of Medical Response Teams (MRTs) in times of accidents and disasters has been one of the measures taken by the health system of different countries to strengthen the capacity to respond to the effects of accidents and disasters. These teams have a self-sufficient structure consisting of professional health experts such as general practitioners and specialists, nurses, midwives, emergency medical technicians, and logistics staff.
These professional staffs are sent to areas whose medical infrastructure has been damaged and do not have sufficient capacity and capability to meet the needs to participate in the process of providing health services [10]. According to the experiences, designing and forming agile and multidisciplinary teams with appropriate training, exercises, and specific management strategies before the occurrence of accidents and disasters will be the most effective way in reducing the impact of accidents and disasters [11].

There is a unique mechanism for disaster risk management in most countries of the world, under which an organization or institution called the Disaster Medical System is responsible for forming MRTs in times of disasters $[11,12]$. The process of preparing these teams to intervene in the response process is influenced by factors such as capacity and capability of different geographical levels such as city, county, province, and region, type of hazards, health effects of hazards, and services expected from these teams [13]. Finally, it can be said that the organizations forming MRTs need to make sure that sufficient care has been taken in the process of selecting members. Appropriate medical examinations, psychological screening, and holding training courses are required. Ensuring security, safety, support, access to medical care, and welfare during deployment [14] are among the essential factors related to the organization and preparation of teams.

The Islamic Republic of Iran is located in a region of Asia where most countries are exposed to various natural hazards [15]. Therefore, personal losses due to disasters and their impacts on the provision of health services have made the issue of health the priority of the disaster management program in Iran [16]. In recent years, the results of studies and experiences related to the process of responding to medical needs affected by accidents and disasters showed that groups of health professionals would attend the disaster-affected areas voluntarily or on-duty. In most cases, the teams were formed without considering the current needs of the region and lacked a coherent organization in terms of management process, composition, specific job description, resources, and facilities. Therefore, it led to chaos, confusion, and discordance in the affected area [2,6]. Given that there is no detailed study on the obstacles and challenges of forming and organizing MRTs in times of disasters in Iran, this study aimed to investigate the obstacles and challenges related to the organization and preparation of these teams and organizations. 


\section{Materials and Methods}

The present study aimed to discover and extract barriers and challenges in organizing and preparing MRTs in times of disasters. Since the adoption of a qualitative approach for studies is only practical when a new field is explored by the exploratory method or to examine it from a new perspective $[16,17]$, a qualitative approach was used with the content analysis method recommended by Graneheim to achieve the purpose of the present study.

\section{Study population}

In qualitative studies, the research environment is an authentic field; that is, the place where the phenomenon occurs, and target participants gain relevant real experiences [18]. Therefore, in the current study, the participants were selected among experts with lived experience in organizing, preparing, dispatching, and deployment of MRTs in the time of disasters. This population included all members of governmental medical organizations (universities of medical sciences, medical and emergency management centers, and military medical systems), non-governmental organizations (Red Crescent Organization, Medical Society Mobilization) which had the relevant experience, accident management knowledge, and expertise related to medical response to accidents and disasters.

\section{Selecting participants}

The strategy for selecting participants in the qualitative studies is usually based on methodology and the study subject [19]. However, the choice of the participants should be appropriate and include participants who are the best source of information for the subject under study. The most common method of selecting participants in qualitative content analysis studies is purposive sampling [20]. In the present study, the participants were selected purposefully with maximum variation and typical patterns.

\section{Data collection method}

The data collection method started with unstructured interviews and then continued with semi-structured and structured questions based on the results of analysis and emergence of categories and subcategories. It should be noted that in addition to the interview method, field visits, and documentation provided by the participants were also used. Data collection was performed from February 2017 to February 2018. After obtaining the informed consent, the interviews were conducted individually, in a quiet environment, at a time and place selected by the participants. All interviews were recorded after obtaining the consent of the interviewee. Finally, 18 interviews were conducted with 16 participants, which lasted between 45 and 75 minutes. Some of the questions posed are listed as examples in the Table 1.

\section{Data management and analysis process}

After the interview, the full text was transcribed word by word; then, each text was analyzed based on the qualitative content analysis method. The approach of Graneheim and Landman (2004) was used for data analysis [21-24]. According to Graneheim, first, the text of each interview, which formed the unit of the analysis, is investigated several times, and its meaning units are identified. The meaning units are, then, summarized so that their main content does not change. Each of the summarized meaning units is assigned a label or code, which are abstract concepts. The codes are then compared with each other based on similarities and differences and then are put under sub-categories and related categories. As interviews progress, concepts and categories are continually compared and categorized to form a general concept with a higher level of abstraction as a theme.

\section{Trustworthiness and rigor of data}

The criteria introduced by Guba and Lincoln (1994) were cited and referred to be ensured the scientific accura-

Table 1. Some examples from the questions asked in interviews

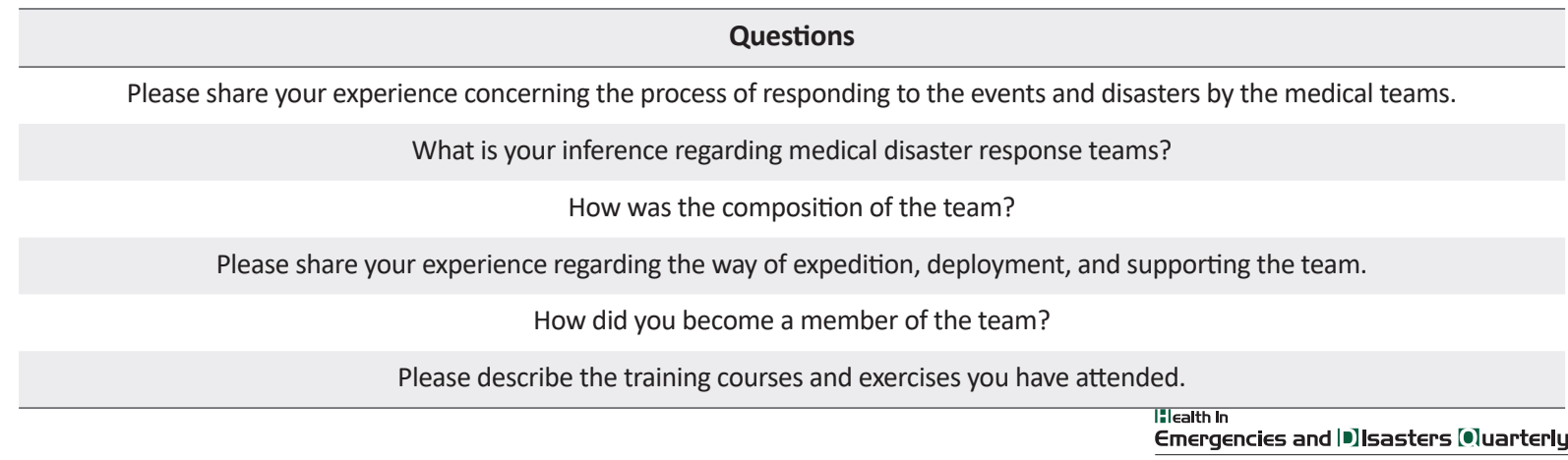


cy of the present study. These criteria included credibility or validity, dependability, transferability, and confirmability, or verifiability [22]. In the present study, the authors tried to increase the validity of the results with long-term involvement and data immersion, member checks, ensuring the consistency of findings with the real experiences of the participants, and external checks. In an external check, the interviews were presented to several observers along with the extraction codes for data analysis.

The reliability of the present study was approved using the accurate recording of interviews, maintaining and preserving them, presenting them to the experts, using external checks, statements, and direct quotations of participants in the final report.

To provide transferability of findings, i.e., the probability of research findings considered significant for others in similar situations, the research team tried to fully describe the field in which the research was conducted by accurately describing the participants, sampling method, time and place of data collection so that the reader does not have any ambiguity regarding the data transferability. To check the validity of the study, from the beginning, the research team tried to register and document all activities to record and report the research process and decisions made during it to accurately check that other researchers can follow up on the research, if necessary.

\section{Results}

In this study, 18 unstructured, semi-structured, and structured interviews were conducted with 16 participants for data collection, including the heads of accident and medical emergency management centers ( 1 person), hospital managers (2 persons), managers of operation management centers ( 2 persons), doctors (3 persons), nurses ( 3 persons), emergency medical experts and technicians ( 3 persons), and members of the medical teams of the Red Crescent Society of the Islamic Republic of Iran ( 2 persons). These individuals had a managerial and operational background in times of accidents and disasters. At the end of the process, obstacles and challenges were obtained in the form of 2 themes, 11 categories, and 31 subcategories. Themes included unorganized groups and fragile readiness.

\section{Unorganized groups}

\section{Team: an unknown structure}

One of the salient points in expressing the experiences and opinions of the participants was the incomplete understanding of the organizations and institutions participating in the response process of the words such as "team" and "team formation". The participants unanimously acknowledged that most structures involved in the disasters formed at the moment and lacked an organized structure as a team. Some participants believed that the structures presented in previous incidents and disasters of the country; at best, they were a "group" of volunteers rather than a cohesive and structured team.

In this regard, one of the study participants (M-07) said: "Actually, these individuals did not come as a team. Team has a definition, any organization of five individuals who come together cannot be called a team. The team must have a structure, a head, and members should know each other and who wants to do what. These individuals form a group at best".

Table 2. Demographic characteristics of the participants

\begin{tabular}{ccc}
\hline Row & Filed of Work / Expertise & Participants (No.) \\
\hline 1 & Head of incident management and emergency medical services (EMS) & 1 \\
\hline 2 & Hospital managers & 2 \\
\hline 3 & Directors of Emergency operation centere (EOC) & 2 \\
\hline 4 & Physician & 3 \\
\hline 5 & Nurses & 3 \\
\hline 6 & Emergency medical technicians & 2 \\
\hline 7 & Active physicians of the Red Crescent Society of the Islamic Republic of Iran & 16 \\
\hline
\end{tabular}


Table 3. Overview of categories, subcategories, and themes

\begin{tabular}{cl}
\hline \multicolumn{2}{c}{ Team management (Fourth-level Concepts (Themes)) } \\
\hline \multicolumn{1}{c}{ Third-level Concepts (Sub-categories): Unorganized groups } \\
\hline & The group instead of the team \\
\hline & Paper-work teams \\
\hline Team: an unknown structure & At-the-moment team \\
& Unstable structure \\
\hline \multirow{3}{*}{ Lack of effective leader/command } & Misunderstanding of command \\
& Poor internal coordination \\
& Incomplete control \\
\hline \multirow{3}{*}{ Weak supervision of organization in charge $\quad$ Lack of responsible administration } \\
& Executive organization: inability to form a team \\
& Emotional membership \\
Membership: a complex process & Unknown identity \\
& Inexperienced member: A burden on the shoulders \\
& Divergent composition \\
Heterogeneous composition & Number of members challenge \\
& The composition changes over time \\
\hline
\end{tabular}

\section{Third-level Concepts (Sub-categories): Fragile readiness}

National level: inability to form a team

Dependability vs. self-sufficiency

Unsystematic support

Inappropriate deployment location
Deficiency under normal circumstances

Insufficient knowledge and skills

Turbulent local management

Disaster-driven approach gap

Lack of standard protocols

Triage: Missed in disasters

Lack of air care team

Lack of individual and group self-sufficiency

Ignorance of the obligation of self-sufficiency

Dependence on local management

Neglecting the presence of the support team

Poor support for local forces

Delayed support

Focusing on multiple structures at a time

Time-consuming deployment of the structure

Instability against weather conditions

Health in

Emergencies and |D]isasters [Oluarterly

\section{Lack of effective leadership/command}

One of the essential pillars of a team is the presence of a leader/commander. The leader/commander is considered as the person accountable for the performance of the team. Based on the experiences and opinions of the participants, there was no proper understanding of this position among the groups and teams present at the events, because most of the teams sent to the af- fected areas did not have a robust command position. Most groups lacked a leader / commander, and those for which someone took responsibility were successful in leading and performing their duties due to the lack of familiarity with the position and the description of its duties. 
Regarding the misunderstanding of the leadership/ command position of the team, one of the participants (M-04) said:

"When we got to the border area and the place of service, the gentleman who was introduced as our commander was with us for three days and then left us without appointing a successor. In the remaining days, we did not have a team leader".

\section{Poor supervision of the responsible organization}

The Ministry of Health and Medical Education, which is responsible for disaster medical response on behalf of the Crisis Management Organization, must oversee the formation and deployment of MRTs. Other supporting organizations that intend to participate in the disaster response process must be under the command of the organization in charge and should be present in the affected areas based on the need and invitation of cooperation with the organization. However, based on the analysis of the participant experiences, in some cases, this institution did not play a governing role. Moreover, teams from other institutions and organizations operated without the supervision of the Ministry of Health".

Concerning the responsible organization forming the team, one of the participants (M-08) said:

"The main organization in charge in this regard is the Ministry of Health. For three or four years, I was the secretary of the rescue task force. It was said that any organization that is normally responsible for a particular service would be responsible for providing service in times of accident and crisis to meet the relevant needs. It does not mean to say that the Red Crescent would provide therapy or health services instead of the Ministry of Health at the time of the accident".

On the other hand, the participants believed that we need a particular structure to form a team and prepare it-a structure whose operational aspects are more pronounced than those of executive activities. The administrative structure can only play an active role in designing, drafting guidelines, and macro-policies. However, training, practicing, equipping, and carrying out operations are required to form a team. In this regard, one of the participants (M-07) said:

"In my opinion, there is, currently, no organization in charge of accident management in the Ministry of Health and medical universities. The Ministry itself, which does not do administrative operations, is a head- quarter where only administrative work is performed. It is the operational tools and arms of the ministry, hospitals, and university networks that can build teams".

\section{Membership: A complex process}

Another critical issue related to the process of forming MRTs in times of disaster is the method of membership. There are different views among the participants in this regard. Some believed in volunteer membership, and others said that members of the medical and paramedical community employed by the Ministry of Health, must be a member of these teams and should participate in missions.

Emotional membership: Since most medical universities do not have pre-designed structures, at the time of the accident and calling medical and paramedical members to be present in the affected areas, a large number of health system employees would volunteer to be sent to these areas based on emotions and excitement resulting from observing the current situation and also based on a sense of commitment. This emotional membership and volunteering will have consequences for the individuals themselves, the dispatch centers, and the management of the areas.

One of the participants (M-07) believed that:

"When unusual situations such as disasters happen, individuals get excited and volunteer to help based on the sense of humanity. I believe that about $85 \%$ of individuals are volunteered to help injured individuals out of excitement or curiosity".

Unknown identity: One of the problems raised by some activists of operation sections was the lack of awareness of the identities of many volunteers who were spontaneously presented in the affected areas. Based on the available evidence and experiences, it was difficult to determine the identities and qualifications of individuals who had arrived in the area individually or as a team.

One of the participants (M-05) mentioned the following in this regard:

"One of our problems was that some individuals came and introduced themselves as doctors. However, we did not know them. The only thing that came to my mind was to say that you are welcomed, but excuse me, do you have an ID card? I asked them for an ID card and then sent it to my colleagues. Of course, I would secretly tell my colleague: "They are doctors, but check if they can work in this position and provide the required services or not". 
Inexperienced member: A burden on the shoulders: One of the practical factors on the effectiveness of MRTs in times of accidents and disasters is the presence of experienced members among the MRTs. According to the participants, many individuals who entered the affected areas as a group or medical response team had no or little previous experience in the field of the response. Based on past experiences, no or little experience of individuals in the field reduces the effectiveness and quality of service.

In this regard, one participant (M-04) mentioned:

"I went to many camps with the Red Crescent and the Martyr Foundation and experienced difficult situations. Nevertheless, most individuals who accompanied us did not understand the situation and had no relevant experience, and they got into trouble because of this. In the event of an accident, it takes two or three days for inexperienced individuals to cope. This lack of adaptation in the first days disrupted our performance, and we could not provide good service".

\section{Heterogeneous composition}

Concerning the composition and number of members in the MRTs at times of accidents and disasters, these factors play an essential role: 1 . a period after the occurrence of danger; 2. level of responsiveness; 3 . existing needs of the region; 4 . the place where the team provides service; and 5 . the place where the team is sent. The most crucial point in this regard is the type of needs in the area that determines the composition and number of team members.

Divergent composition: Analysis of the experiences and opinions of some participants shows that most teams present in accidents and disasters have a heterogeneous composition. Asymmetric composition refers to issues such as the mismatch between the number of medical and non-medical members. It also refers to a mismatch between the specialties and the gender of the members. According to the participants, lack of balance and appropriateness in the team composition can cause ethical and professional challenges, reduce the quality of service, staff fatigue and burnout, and patient dissatisfaction.

One participant (M-03) said the following in this regard:

"Concerning the clinicians, I have to say that we had 5 doctors a day, and there was a day when we had only 2 doctors. Sometimes I would ask the doctor of the nearby clinic, which belonged to the police force, to be present in our clinic for 2 hours and visit the clients".
Number of members: an underlying challenge: One of the challenges related to the composition of MRTs is the number of members of these teams. The participants had different opinions about the number of members in the teams. Some believed in the formation of small and agile teams according to the standard of the limited monitoring, i.e., 5-7 members. These teams can be called and sent in a short time. However, some participants believed that it was easier to manage a large and complete team that was sent to the area with a combination of different specialties to meet different needs than to manage several small teams.

In this regard, one participant (M-12) stated:

"The 5-person combination of the general practitioner, nurse, midwife, and emergency technician seemed to be more effective. Calling and sending large teams to the front line of dealing with patients and injured due to the earthquake causes a waste of time and increases mortality and injuries. I have to say that preparing a big team in the first moments of the incident is difficult in terms of management and organization, and we will lose time".

\section{Fragile preparation}

\section{Local level: Inability to form a team}

According to some participants, due to a lack of human resources, medical and non-medical equipment, a team cannot be formed at the local level. Since most cities and some provinces have faced a shortage of professional human resources under normal circumstances and most of these resources are in the form of compulsory training courses and temporary workforces, it is difficult to form stable teams at this level.

One participant (M-16) believed that:

"In deprived provinces and cities, we can form teams at the university level. However, at the network level and below, we are unable to form a team because we do not have a fixed workforce and sufficient facilities. On the other hand, we have limited power and capacity in these areas and at the network level. We suffer from this weak capacity at the time of the accident".

\section{Disaster medicine: A strange concept}

One of the concepts derived from the participants' experiences concerning the medical response to disasters was "Disaster medicine: A strange concept". Based on the experiences and perspectives of most participants, one of the main challenges in terms of capacity and capability is the unfamiliarity and the lack of complete un- 
derstanding of the principles of disaster medicine by the groups and teams present at the scene of accidents and disasters.

The following was mentioned by one of the participants (M-01) in this regard:

"I have to say that our staff has good skills in managing every one of the injured and can manage an injured well. However, when emergency medical technicians are supposed to manage 10,20 , or 30 injured individuals at a time in a particular accident, they run into contradictions and face skill problems".

On the other hand, in most parts of the country, local staff are not familiar with medical issues in times of disaster. As the number of patients increases in accidents and disasters, the staff cannot change the caring approach of a typical situation to that of the disaster.

Regarding the lack of familiarity with the principles of disaster medicine, one of the participants (M-02) said:

"Almost everyone was trying to do a job. For example, I cared a casualty, and then another colleague came and provided service for the same person. We did not know who was responsible for which of the injured".

\section{Lack of air care team}

We need a skilled care team to transport patients by plane and helicopter. The point made in the experiences of participants was the lack of a sufficient number of patient care teams in the air care process.

One participant (M-06) mentioned:

"We had a problem with the air care team. Each helicopter needed at least two experienced technicians to take care of the patients, but unfortunately, we did not have them. Not every doctor, nurse, or emergency medical technician can participate in air transport. Air emergency care teams need special training”.

\section{Dependence vs. self-sufficiency}

One of the critical issues in the process of sending MRTs to the affected areas is the need for the teams to be selfreliant during the deployment period. The issue of selfsufficiency was one of the topics most participants noted its absence among the groups present. According to the opinions and experiences of participants, there was no concept of "complete self-sufficiency" among individuals and groups present in the area. According to the results, individuals and most groups have been dependent on local managers in terms of basic needs such as nutrition, housing, primary health services, and in terms of transportation and supplying technical and medical equipment.

Regarding the lack of self-sufficiency of groups and volunteers in the events, one participant (M-14) said:

"After the earthquake, many individuals came to the area individually or as a team. I can say that they did not have equipment and support with them. We had to provide them with water and food. We had to provide them a place for rest. I can say that only individuals came, and they had no logistics and equipment".

\section{Unsystematic support}

One of the points made by the participants was the lack of systematic support for the teams in the operation area. From one perspective, the participants' views should be respected on issues such as energy supply, structural erection, equipment maintenance, nutrition, and other non-medical services, which requires a team of expert members in these cases. The presence of these individuals, along with the response teams, will facilitate and meet their needs.

One participant (M-06) believed that:

"Some of the forces we sent to the area were not supported there. For example, we took emergency medicine to a place where there were just a stethoscope and a sphygmomanometer, and they had no other equipment".

Another concept of supporting the participants' point of view implies the existence of a supportive medical team to move or replace the team in case of fatigue.

One participant (M-04) stated that:

"The next problem was the lack of professional staff. Only 10 doctors and 2 nurses were sent for 10 days of deployment and continuous service. These individuals should cover morning and evening shifts. It has caused extreme fatigue and illness to all medical staff due to long working shifts and a large number of patients".

\section{Improper location}

Since most of the accidents that occurred in the country were geological hazards, especially earthquakes, which were followed by the destruction of structures and infrastructure, there was a need for facilities. In locating the facility, several factors are involved, such as proximity to 
the accident site and patient assembly centers, safety and security of the facility, access to critical infrastructures such as energy, water, communications, and transportation. Another critical issue is the access of the affected population to the relief teams that are responsible for moving and transporting patients. According to the participants, the facilities of the working area are not correctly located, so that it causes dysfunction itself.

Concerning the deployment of mobile facilities in one geographical site, one participant (M-16) said:

"One of our problems was that all the injured and patients were brought to the hospital from all areas. By the third day, four field hospitals were established there: Army, Islamic Revolutionary Guards Corps, University of Medical Sciences, and Red Crescent field hospitals. However, the problem was that all patients gathered together in one site, and people had to bring their patients from the town and the surrounding villages".

\section{Discussion}

The present study was designed and conducted to investigate the structural status and preparedness of the teams present in the past accidents and disasters of the country. Finally, the obstacles and challenges related to the organization and preparation of teams were achieved in the form of 2 themes, 11 categories, and 5 subcategories. Themes included unorganized groups and fragile readiness. The first theme comprised the concepts of A. Team: An unknown structure; B. Lack of efficient leadership/command; C. Weak supervision of the organization in charge; D. Membership: A complex process; e. Heterogeneous combination of categories. The second theme concepts were: A. Local level: Inability to form a team; B. Disaster medicine: A strange concept; C. Lack of air care team; D. Dependence on self-sufficiency; E. Unsystematic support; and F. Improper location.

The results of the study showed that the existing structures for medical response to disasters had faced many obstacles and challenges in the field of organization and preparedness. This chapter provides a comprehensive interpretation of the study findings and compares it with the results of other studies.

\section{Organizing and preparing the team}

The results of the present study showed that despite the designation of the Ministry of Health and Medical Education as the organization responsible for responding to the health needs in times of accidents and disas- ters assigned by the Crisis Management Organization, this ministry plays no role in the formation and general management of MRTs at times of events and disasters as it should be and perhaps as the primary organization in charge of designing guidelines. In the structure of MRTs in the world, a specific organization or institution is responsible for forming disaster response teams.

According to the study by Akbari et al. (2019), in most countries of the world, the responsibility of medical response to the effects of accidents and disasters is on the Ministry of Health. Therefore, disaster response or medical assistance teams have been established directly by the Ministry of Health or other public and private institutions under the supervision of the Ministry of Health [8]. Therefore, according to the strict letter of the law and the emphasis of the participants, The Ministry of Health and Medical Education is in charge of the MRTs in the country. It is recommended that a department should be established to develop guidelines and structures for the formation of disaster response teams under the supervision of the Health Disaster Working Group.

The process of the command chain for responding to accidents and disasters is specified at the national and local levels and all their subdivisions [23]. This process is specified within the framework of the national response of the country to the disasters. According to the results of the study, most of the groups sent to the affected areas did not have a strong leadership/command position. Based on the experiences and opinions of the participants, there was no correct understanding of the position of leadership/command in the groups and teams formed and present at the place of events. Based on a study by Peter Aitken et al. (2012) to ensure clear communication and coordination in inter-organizational response, cooperation, and collaboration requires a strong command structure. Failure in the command structure may lead to discrete or ineffective responses in the form of negligence and rework [24].

In line with the results of the present study, Oldenburger et al. (2017) stated that team leaders are responsible for facilitating teamwork by guiding and facilitating members' communication with each other [25]. Hisayoshi Kondo (2009), while describing the process of deployment of medical aid teams in the disasters of Japan, stated that the teams arriving at the scene of the accident were required to provide services under the supervision and command of the operational team stationed in the area [26-29]. Based on the findings of the participants' experiences, the existence of a leadership/command structure in disaster response teams is necessary to lead, 
control, and create internal and external coordination, create cohesion in the team, and ensure the safety of members.

To participate in MRTs in accidents and disasters, having the following features are essential: the willingness of professionals to have an employment relationship with the Ministry of Health, Medical Treatment and Education, the experience of presence in the place of disasters, knowledge, and skills related to disaster medicine in accordance with a valid certificate, health, and physical and mental readiness, the ability to work in severe disaster conditions and to comply with the constraints in the region. According to the results of the study by Akbari et al. (2019) and in compliance with the existing guidelines for designing and organizing teams in the United States, New Zealand, and the World Health Organization, health professionals voluntarily join teams and after announcing their readiness, their conditions will be evaluated based on the standards set in each of the structures. If the existing characteristics are matched with the set conditions, the individuals will become members [8].

Items such as having a valid certificate and license in the field of a specialized area, citizenship documents, a valid passport for being sent to international missions, previous experience in disaster medical response, availability on-call, adaptability and resilience to stressful events and situations, the ability to communicate appropriately with colleagues and patients, the ability to work with specialized equipment and communication are among the conditions of membership in these structures [27-30]. This finding was mostly consistent with the findings of the present study. The findings of the present study are in line with the results of the study by Oldenburger et al., which mentioned features such as adaptability, flexibility, experience, and training for volunteer members of disaster response teams [25].

Regarding the requirement of physical fitness and mental health of members, the findings of the study by Peter Aitkin (2009) and Holland (2004) point out that having enough knowledge and skills to join medical disaster response teams. In addition to these indicators, physical and mental health, personality traits such as motivation, ability to work in a team, and skills in fieldwork should also be considered $[31,32]$. Therefore, the findings of the present study are in line with those of their study.

Regarding the composition of the medical response team, it is recommended that; A. The team should be formed in the form of a multidisciplinary team with the presence of medical and non-medical members; B.
In order not to lose the golden time to attend the acute phase after accidents and disasters, it is recommended to form small and agile teams with 5 to 7 members. These recommendations are in line with those of the study by Akira Fuse (2010) and Parveen Parmar (2013). They mentioned in their study that factors such as the geographical location of the accident, the type of risk, the medical needs of the affected region play essential roles concerning the composition of the teams [33, 34].

In this regard, the Japan Disaster Medical Assistance Team (J-DMAT) aimed for participation in the rapid medical response to the chief danger of the country, i.e., the earthquake, has 4 to 5 members [34]. The proposed combination of participants is different from that of some structures such as the Australian Medical Assistance Team (AusMAT), which has a minimum of 15 and a maximum of 40 members [35] and the World Health Organization Emergency Medical Teams (EMTs) designed to participate in national and international disasters $[30,36]$.

Improving the level of preparedness for the appropriate response requires designing and forming a team at different levels from the lowest level, which is a comprehensive health network to the highest level, which is at the national level. Differences observed in the activity levels of teams in different countries are affected by factors such as capacity and capability at different levels of political divisions (city, county, province, and region), the goals of team formation, the type of risks and their consequences, and the organization responsible for forming the team [13]. In his study, Akira Foss (2010) stated that in Japan, given that earthquakes are the predominant risks, teams are formed at the local level with a focus on disaster-based hospitals to be dispatched to the affected areas immediately after identification of the need [33].

Given the importance of timely and effective response in the acute phase of the accident, participants prioritize strengthening the capacity and capability of the health sector at the local level by promoting knowledge, skills, and forming small and agile teams. This recommendation is consistent with a study by Boyd et al. (2014), which stated that disaster planning seeks to use resources efficiently at the local, regional, and national scales [9]. In his study, Arziman stated that most of the immediate and primary care in accidents and disasters is provided by local staff. According to him, the limited resources of these staff should be matched with the needs of the area [10]. Rifino also points out in a disaster health science resource that due to the late presence of MRTs outside the affected area, especially international teams, are critical 
to providing an efficient response based on local capacity and capability in the first 72 hours after an accident [37].

The competence of respondents to the effects of disasters is one of the critical components in the success of intervention programs. Creating and enhancing the capacity of respondents before dispatch and deployment is a kind of investment of the organizations that form the response teams $[38,39]$. Adopting a coherent educational approach to improve the quality and professionalism of expedition teams is considered an essential step in preparing teams [40]. Concerning members' knowledge and skills in responding to accidents and disasters, the concept of the extracted class indicated that most of the members in the teams were unfamiliar with the principles of disaster medicine.

These findings are consistent with the results of the study by Nakhaei et al. (2015). They stated that relief teams present in the affected area without a written action plan, clear job description, and lack of necessary facilities and equipment, have caused confusion and chaos in the response process. Unprepared presence in terms of lacking the appropriate program and equipment has not only reduced efficiency but also disrupted coordination [2]. Based on the analysis of participants' opinions, although instructions have been developed by the Health Working Group on Accidents and Disasters and sent to the health system subdivisions, there are some shortcomings in the training process.

This finding is consistent with the results of the study by Jalali et al. (2014). The study noted that training programs on disaster risk management were not successful for reasons such as the following: A. Lack of competency-based and comprehensive training and skills development programs; B. Low quality and quantity of educational programs; C. Lack of standard criteria in how to select members of disaster training courses; D. A limited number of professional trainers to teach the principles of disaster risk management [41]. Finally, it should be noted that all countries and organizations in charge of forming a medical response team in disasters have special education training programs based on the type of team, the scope of responsibility, description of tasks, and level of intervention of teams at the time of deployment which are repeated continuously and at regular intervals throughout the year [13, 29, 42-44].

Support and logistics are essential elements of many international models of disaster response $[45,46]$. One of the crucial issues related to MRTs is supporting these teams after the expedition and deployment in the area. It is im- perative that which organization supports the team in terms of technical, non-technical, and basic needs at the time of expedition in the affected area. As participants mentioned, most teams experienced many challenges for supporting and assistance in past disasters. Experience and observations show that most teams or groups present in the affected areas have been dependent on local management in terms of meeting basic needs and sometimes for procurement. This feature of the groups present in their area has been a factor in increasing the dysfunction in service provision.

The above findings are consistent with the results of the study by Jalali et al. (2011). According to the results of this study, the lack of resources in the earthquake-stricken region of Bam was one of the points mentioned. Medical teams lacked enough equipment at the time of deployment in the acute phase, and on the other hand, the destruction of medical facilities worsened the situation and led to disruption in the provision of services during that vital period [48]. The study results showed that medical and disaster response teams sent to the affected areas should be completely self-reliant in terms of medical, non-medical, and welfare equipment for at least 72 hours; they should not need help and assistance outside their structure.

This recommendation is in line with the results of a study by Peter Aitkin et al., in which the author noted that MRTs must be fully self-reliant for at least 72 hours and operate without the need for external resources at the time of arrival to the affected area [48]. Participants' recommendations in the present study are also in line with the results of the study by Albina et al. (2018). In their study, it was recommended that all teams should be self-reliant in providing shelter, food, water, sewerage, and all the tools and equipment necessary for the initial stage of response [49]. Describing the process of deploying medical aid teams in the Japan disaster, Hisayoshi Kondo (2010) pointed out that supportive aids in areas such as security, proper communication, facilitating the transfer of members, providing medical equipment necessities and living necessities to provide appropriate services by response teams in the area affected by accident is mandatory [26].

\section{Conclusion}

A prompt and appropriate response to the first and most urgent needs and concerns of individuals affected by accidents and disasters, i.e., the need to receive health services, is one of the fundamental pillars of disaster risk management. The results of the present study showed that due to the sudden increase in medical needs, damage and destruction of health facilities infrastructure in the first minutes and hours after the occurrence of accidents 
and disasters in the affected area, the health sector should be strengthened to respond quickly and appropriately to the human casualties of disasters. It is possible by building and strengthening capacity through the proper organization and preparation of MRTs at times of disasters.

The results of this study and its comparison with other existing studies showed that medical teams present in disaster-affected areas had had several challenges in the process of organizing and preparing, through which they have not been able to provide an appropriate response to the affected population. The results of the present study indicated the need to design and form structured, self-reliant, and agile MRTs for a timely and appropriate response. It is attained with a suitable combination of experienced and trained members with a specific process of support from the operations guidance center to be able to perform their duties under the supervision of the Health Working Group on Accidents and Disasters of the Ministry of Health and Medical Education.

\section{Study Suggestions}

Since the present study aimed to explore the barriers and challenges associated with organizing and preparing MRTs, other aspects involved in the process of managing MRTs in disasters such as legal, health, safety, and security considerations have not been taken into account. Therefore, researchers recommend a comprehensive study to clarify the status of these teams in all their divisions and characteristics.

\section{Ethical Considerations}

\section{Compliance with ethical guidelines}

The present study was registered in the Ethics Committee of the University of Social Welfare and Rehabilitation Sciences with the (Code: IR.USWR.REC.1396.255). Before starting each interview, the implied consent of the participants was obtained regarding recording their voices. Besides, they were reminded that whenever they felt unwilling to collaborate or share their experiences, they could withdraw from the study. Since the research team, like all other studies, is responsible for the trustworthiness of data, this case was true for the present study.

\section{Funding}

This article is part of Yosouf Akbari Shahrestanaki's $\mathrm{PhD}$ dissertation, that did not receive any grant from funding agencies in the public, commercial, or non-profit sectors.

\section{Authors' contributions}

Yosouf Akbari Shahrestanaki: Data gathering, data analysis and writing the manuscript draft; Hamidreza Khankeh: Supervising, methodological desigining, and draft preparation; Gholamreza Masoumi: Data analysis, and editing the draft; Mohammadali Hosseini: Data analysis and editing

\section{Conflict of interest}

The authors declare no conflict of interests.

\section{Acknowledgments}

The research team would like to thank all participants who patiently assisted in the data collection process.

\section{References:}

[1] Khankeh HR, Masoumi G. Hospital disaster risk management: national plan. Tehran: University of Social Welfar \& Rehabilitation; 1396.

[2] Nakhaei M, Khankeh H, Masoomi G, Hosseini Ma, Parsa Yekta Z. Health management in disasters in Iran: A qualitative study. Health Emerg Disasters Q. 2015; 1(1):33-41. https://www.sid.ir/en/journal/ViewPaper.aspx?id=471811

[3] Lin X, Liu K-J, Zhang Y-G, Dan Y, Xing D-G, Chen L, et al. China medical team: Medical rescue for " 4.25 " Nepal earthquake. Chin J Traumatol. 2017; 20(4):235-9. [DOI:10.1016/j. cjtee.2017.04.004] [PMID] [PMCID]

[4] Yaghmaei N. Disasters 2018: Year in Review. Centre for Research on the Epidemiology of Disasters (CRED). 2018; 54 [DOI:10.13140/RG.2.2.28419.55840]

[5] Debacker M, Van Utterbeeck F, Ullrich C, Dhondt E, Hubloue I. SIMEDIS: A discrete-event simulation model for testing responses to mass casualty incidents. J Med Syst. 2016; 40(12):273. [DOI:10.1007/s10916-016-0633-z] [PMID] [PMM CID]

[6] Pourhosseini SS, Ardalan A, Mehrolhassani MH. Key aspects of providing healthcare services in disaster response stage. Iran J Public Health. 2015; 44(1):111-8. [PMID] [PMCID]

[7] Guzmán IB, Cuesta JG, Trelles M, Jaweed O, Cherestal S, van Loenhout JAF, et al. Delays in arrival and treatment in emergency departments: Women, children and non-trauma consultations the most at risk in humanitarian settings. PLoS One. 2019; 14(3):e0213362. [DOI:10.1371/journal.pone.0213362] [PMID] [PMCID]

[8] Akbari Shahrestanaki Y, Khankeh H, Masoumi G, Hosseini $M$. What structural factors influencing emergency and disaster medical response teams? A comparative review study. J Edu Health Promot. 2019; 8(1):110. [DOI:10.4103/jehp. jehp_24_19] [PMID] [PMCID] 
[9] Boyd A, Chambers N, French S, Shaw D, King R, Whitehead A. Emergency planning and management in health care: Priority research topics. Health Syst. 2014; 3(2):83-92. [DOI:10.1057/hs.2013.15] [PMID] [PMCID]

[10] Koenig KL, Schultz CH. Koenig and Schultz's disaster medicine: Comprehensive principles and practices. $2^{\text {nd }}$ edition. Cambridge: Cambridge University Press; 2016. [DOI:10.1017/CBO9781139629317]

[11] Aitken P, Leggat P, Harley H, Speare R, Leclercq M. Human resources issues and Australian disaster medical assistance teams: Results of a national survey of team members. Emerg Health Threats J. 2012; 5(1):18147. [DOI:10.3402/ehtj. v5i0.9750] [PMID] [PMCID]

[12] Arziman I. Field organization and disaster medical assistance teams. Turk J Emerg Med. 2016; 15(Suppl. 1):11-9. [DOI: 10.5505/1304.7361.2015.79923] [PMID] [PMCID]

[13] Sklar DP, Richards M, Shah M, Roth P. Responding to disasters: academic medical centers' responsibilities and opportunities. Acad Med. 2007; 82(8):797-800. [DOI:10.1097/ ACM.0b013e3180d0986e] [PMID]

[14] Ministry of Health. New Zealand Health Emergency Medical Assistance Team (NZMAT) Operational Manual. Wellington: Ministry of Health; 2012. https:/ / www.health.govt.nz/ publication/new-zealand-health-emergency-medical-assistance-team-nzmat-operational-manual

[15] Norton I, Von Schreeb J, Aitken P, Herard P, Lajolo C. Classification and minimum standards for foreign medical teams in sudden onset disasters. Geneva: World Health Organization; 2013.

[16] Djalali A, Castren M, Khankeh H, Gryth D, Radestad M, Öhlen G, et al. Hospital disaster preparedness as measured by functional capacity: 'comparison between Iran and Sweden. Prehosp Disaster Med. 2013; 28(05):454-61. [DOI:10.1017/ S1049023X13008807] [PMID]

[17] Khankeh HR, Khorasani-Zavareh D, Johanson E, Mohammadi R, Ahmadi F, Mohammadi R. Disaster health-related challenges and requirements: A grounded theory study in Iran. Prehosp Disaster Med. 2011; 26(03):151-8. [DOI:10.1017/ S1049023X11006200] [PMID]

[18] Corbin J, Strauss A. Basics of qualitative research: Techniques and Procedures for Developing Grounded Theory. New York: Sage; 2014. https://us.sagepub.com/en-us/ nam/basics-of-qualitative-research/book 235578

[19] Polit DF, Beck CT. Nursing research: Principles and methods. Philadelphia: Lippincott Williams \& Wilkins; 2012 https://books.google.ro/books/about/Nursing_Research. html?id=5g6VttYWnjUC\&redir_esc $=y$

[20] Munhall PL. Nursing research. Sudbury: Jones \& Bartlett Learning; 2012. https://www.jblearning.com/ nursing-medicine/nursing/research-theory/productdetails/9780763785154

[21] Higginbottom GMA. Sampling issues in qualitative research. Nurse Res. 2004; 12(1):7-19. [DOI:10.7748/ nr2004.07.12.1.7.c5927] [PMID]

[22] Elo S, Kääriäinen M, Kanste O, Pölkki T, Utriainen K, Kyngäs H. Qualitative content analysis: A focus on trustworthiness. SAGE Open. 2014; 4(1):2158244014522633. [DOI:10.1177/2158244014522633]
[23] Graneheim UH, Lundman B. Qualitative content analysis in nursing research: concepts, procedures and measures to achieve trustworthiness. Nurse Educ Today. 2004; $\backslash 24(2): 105-$ 12. [DOI:10.1016/j.nedt.2003.10.001] [PMID]

[24] Lincoln YS, Guba EG, Pilotta JJ. Naturalistic inquiry: Beverly Hills, CA: Sage Publications, 1985, 416 pp., \$25.00 (Cloth). Int J Intercult Relat. 1985; 9(4):438-9. [DOI:10.1016/01471767(85)90062-8]

[25] Organization NE. National Response Framwork. Tehran, Iran: Ministry of Health; 2018.

[26] Aitken P, Leggat PA, Robertson AG, Harley H, Speare R, Leclercq MG. Leadership and use of standards by Australian disaster medical assistance teams: Results of a national survey of team members. Prehosp Disaster Med. 2012; 27(2):142-7. [DOI:10.1017/S1049023X12000489] [PMID]

[27] Oldenburger D, Baumann A, Banfield L. Characteristics of medical teams in disaster. Prehosp Disaster Med. 2017; 32(2):195-200. [DOI:10.1017/S1049023X16001461] [PMID]

[28] Kondo H, Koido Y, Morino K, Homma M, Otomo Y, Yamamoto $Y$, et al. Establishing disaster medical assistance teams in Japan. Prehosp Disaster Med. 2009; 24(6):556-64. [DOI:10.1017/S1049023X00007512] [PMID]

[29] Juan Ortega BS, R.N. . What is a Disaster Medical Assistance Team (DMAT)? West Central Florida Disaster Services, Inc: FL-3 Disaster Medical Assistance Team; 2018. Available from: http://www.fl3dmat.org/.

[30] Ministry of Health. Applying to volunteer with NZMAT. Wellington: Ministry of Health; 2020 [Updated 2020 February 14]. Available from: https://www.health.govt.nz/ourwork/emergency-management/new-zealand-medical-assistance-team/volunteering-nzmat/applying-volunteer-nzmat.

[31] Günaydın M, Tatlı Ö, Ersöz Genç E. Arama Kurtarma Örgütleri ve UMKE. Nat Disaster Environ Mag. 2017; 3(1):5663. [DOI:10.21324/dacd.267345]

[32] Norton I, Von Schreeb J, Aitken P, Herard P, Lajolo C. Classification and minimum standards for foreign medical teams in sudden onset disasters. Geneva: World Health Organization. 2013. https://www.who.int/csr/resources/publications/ebola/foreign-medical-teams/en/

[33] Aitken P, Leggat P, Robertson A, Harley H, Speare R, Leclercq M. Pre-and post-deployment health support provided to Australian disaster medical assistance team members: results of a national survey. Travel Med Infect Dis. 2009; 7(5):305-11. [DOI:10.1016/j.tmaid.2009.03.001]

[34] Holland J, Wooster P. International rescue team: selection and training. Crisis Response J. 2004; 1(1):51-4.

[35] Fuse A, Yokota H. An analysis of Japan Disaster Medical Assistance Team (J-DMAT) deployments in comparison with those of J-DMAT's counterpart in the United States (USDMAT). J Nippon Med Sch. 2010; 77(6):318-24. [DOI:10.1272/ jnms.77.318] [PMID]

[36] Parmar P, Arii M, Kayden S. Learning from Japan: Strengthening US emergency care and disaster response. Health Aff. 2013; 32(12):2172-8. [DOI:10.1377/hlthaff.2013.0704] [PMID]

[37] National Critical Care and Trauma Response Centre. Australian Medical Assistance Team Training: AusMAT. 2011. 
[38] World Health Organization. Emergency Medical Teams (EMT) Initiative. Geneva: World Health Organization; 2017.

[39] Rifino JJ, Mahon SE. Role of emergency medical services in disaster management and preparedness. In: Ciottone GR, (Editor). Ciottone's Disaster Medicine, $2^{\text {nd }}$ edition. Amsterdam: Elsevier; 2016. [DOI:10.1016/B978-0-323-28665-7.00003-0]

[40] Cranmer HH, Biddinger PD. Typhoon Haiyan and the professionalization of disaster response. N Engl J Med. 2014; 370(13):1185-7. [DOI:10.1056/NEJMp1401820] [PMID]

[41] Van Hoving DJ, Wallis LA, Docrat F, De Vries S. Haiti disaster tourism - A medical shame. Prehosp Disaster Med. 2010; 25(3):201-2. [DOI:10.1017/S1049023X00008001] [PMID]

[42] Camacho NA, Hughes A, Burkle Jr FM, Ingrassia PL, Ragazzoni L, Redmond A, et al. Education and training of emergency medical teams: recommendations for a global operational learning framework. PLoS Curr. 2016; 8:ecurrents.dis.2 92033689209611ad5e4a7a3e61520d0. [DOI: 10.1371/currents. dis.292033689209611ad5e4a7a3e61520d0] [PMID] [PMCID]

[43] Djalali A, Ingrassia PL, Della Corte F, Foletti M, Gallardo $\mathrm{AR}$, Ragazzoni L, et al. Identifying deficiencies in national and foreign medical team responses through expert opinion surveys: Implications for education and training. Prehosp Disaster Med. 2014; 29(4):364-8. [DOI:10.1017/S1049023X14000600] [PMID]

[44] Murray JS. National disaster medical system. Am J Nurs. 2012; 112(2):58-63. [DOI:10.1097/01. NAJ.0000411181.86094.2b] [PMID]

[45] National Critical Care and Trauma Response Centre. Australian Medical Assistance Teams (AUSMAT) [Internet]. 2011 [Retrieved 2020 December 02] Available from: https://www.nationaltraumacentre.nt.gov.au/what-we-do/disaster-management/ausmat

[46] Anan H, Akasaka O, Kondo H, Nakayama S, Morino K, Homma M, et al. Experience from the great east Japan earthquake response as the basis for revising the Japanese disaster medical assistance team (DMAT) training program. Disaster Med Public Health Prep. 2014; 8(6):477-84. [DOI:10.1017/ dmp.2014.113] [PMID]

[47] Bar-Dayan Y, Leiba A, Beard P, Mankuta D, Engelhart D, Beer Y, et al. A multidisciplinary field hospital as a substitute for medical hospital care in the aftermath of an earthquake: The experience of the Israeli defense forces field hospital in Duzce, Turkey, 1999. Prehosp Disaster Med. 2005; 20(2):103-6. [DOI:10.1017/S1049023X00014370] [PMID]

[48] Koido Y. Activities of Japanese disaster relief teams against the tsunami disaster in the Indian Ocean. Prehosp Disaster Med. 2005; 20(S2):S118-S. [DOI:10.1017/S1049023X00014606]

[49] Djalali A, Khankeh H, Öhlén G, Castrén M, Kurland L. Facilitators and obstacles in pre-hospital medical response to earthquakes: A qualitative study. Scand J Trauma Resusc Emerg Med. 2011; 19(1):30. [DOI:10.1186/1757-7241-19-30] [PMID] [PMCID] 